\title{
Insulin-independent and wortmannin-resistant targeting of IRS-3 to the plasma membrane via its pleckstrin homology domain mediates a different interaction with the insulin receptor from that of IRS-1
}

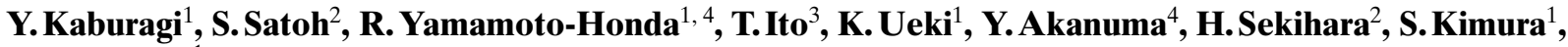 \\ T. Kadowaki ${ }^{1}$ \\ ${ }^{1}$ The Department of Metabolic Disease, Graduate School of Medicine, University of Tokyo, Bunkyo-ku, Tokyo, Japan \\ ${ }^{2}$ The Third Department of Internal Medicine, School of Medicine, Yokohama City University School of Medicine, Yokohama, \\ Japan \\ ${ }^{3}$ The Department of Pathology, School of Medicine, Yokohama City University School of Medicine, Yokohama, Japan \\ ${ }^{4}$ The Institute for Diabetes Care and Research, Asahi Life Foundation, Tokyo, Japan
}

\section{Abstract}

Aims/hypothesis. In primary adipocytes, although IRS-1 and IRS-3 are expressed in comparable amounts, these proteins manifest distinct distribution and significance in insulin signalling. We investigated the molecular basis of the difference between these two proteins.

Methods. In Cos-1 cells transiently expressing rat IRS-1, IRS-3, or chimeric proteins of these two proteins we examined the tyrosine phosphorylation via the wild-type or mutant insulin receptors and evaluated their targeting to the plasma membrane by immunostaining the membrane ghost.

Results. In contrast to IRS-1, IRS-3 was tyrosine-phosphorylated by the insulin receptor altering $\mathrm{Tyr}^{960}$ to Phe (Y960F), which disrupts the binding site of the PTB domain of IRSs, to an extent comparable to the wild-type receptor. The tyrosine phosphorylation of
IRS-3 with the PH domain replacement via the Y960F insulin receptor markedly decreased, whereas that of IRS-3 with the PTB domain alteration was mildly impaired. Insulin-stimulated translocation of IRS-1 to the plasma membrane, as well as that of IRS-3 with the PH domain replacement, was wortmannin-sensitive, although that of IRS-3 was insulinindependent and wortmannin-resistant.

Conclusions/interpretation. The affinity of the $\mathrm{PH}$ domain for the phospholipids in the plasma membrane seems to influence the receptor-substrate interaction required for IRS tyrosine phosphorylation, indicating that the PH domain and the PTB domain of IRSs cooperatively function in insulin-stimulated tyrosine phosphorylation of these proteins. [Diabetologia (2001) 44: 992-1004]

Keywords Insulin, insulin receptor, IRS-1, IRS-3, PH domain, PTB domain, PI 3-kinase.
Received: 17 October 2000 and in revised form: 27 March 2001

Corresponding author: Dr. T.Kadowaki, The Department of Metabolic Disease, Graduate School of Medicine, University of Tokyo, 7-3-1 Hongo, Bunkyo-ku, Tokyo 113-8655, Japan. E-mail: kadowaki-3im@h.u_tokyo.ac.jp

Abbreviations: IRS, insulin receptor substrate; SH, src homology; PH, pleckstrin homology; PTB, phosphotyrosine binding; NPXpY, tyrosine-phosphorylated NPXY; Y960F insulin receptor, the insulin receptor (Ullrich-type) in which the juxtamembrane $\mathrm{Tyr}^{960}$ was altered to Phe; $\alpha \mathrm{PY}$, an antibody specific for phosphotyrosine; $\alpha \mathrm{HA}$, antibodies against haemagglutinin; $\alpha \operatorname{IR} \beta$, antibodies against the $\beta$ subunit of human insulin receptor; FITC, fluorescein isothiocyanate; TRITC, tetramethyl rhodamine isothiocyanate; DAPI, 4', 6-diamine-2'-phenylindole dihydrochloride; HA, haemagglutinin; PM, plasma membrane; IRS3-X・IRS1, chimeric IRS-3 in which its domain X is replaced with that of IRS-1; GFP, green fluorescent protein
Insulin binding activates the insulin receptor tyrosine kinase leading to tyrosine phosphorylation of endogenous substrates such as insulin receptor substrates (IRSs) [1-4], Gab1 [5], and Shc [6]. Subsequent to tyrosine phosphorylation, these proteins bind various Src homology (SH) 2 domain-containing proteins which mediate various biological processes. Recently, four members of the IRS family have been cloned [1$4,7]$. These molecules have a similar structure and contain in the following order from the $\mathrm{N}$ terminus: a pleckstrin homology $(\mathrm{PH})$ domain which is considered to be involved in the interaction with phospholipids, a phosphotyrosine binding (PTB) domain which directly binds to the tyrosine-phosphorylated NPXY (NPXpY) motif containing Tyr ${ }^{960}$ in the juxtamembrane region of the insulin receptor, and a C-ter- 
minal domain with a number of tyrosine phosphorylation sites that can bind various $\mathrm{SH} 2$ domain-containing proteins [8]. In addition to insulin and insulin-like growth factor-I, IRSs have been shown to play a role in mediating the actions of cytokines $[8$, 9]. Moreover, the recent discovery of an IRS homologue CHICO in Drosophila suggests that the insulin receptor/IRS axis could be an evolutionally conserved pathway which controls growth and metabolism [10].

Recently, the physiological roles of all four members of this family were examined by generating mice with a targeted disruption of IRS-1, IRS-2, IRS-3 or IRS-4 gene loci [11-15]. Despite the structural similarities between the IRSs, analyses of these mice showed that IRSs have different functions in development and metabolism. Mice lacking IRS-1 have retarded growth and insulin resistance, although there was no difference in the concentrations of blood glucose before and after uptake of glucose [11, 12]. In contrast, mice lacking IRS-2 are only slightly smaller than wild-type but progressively manifest diabetes due to both insulin resistance and reduced betacell mass [13]. Mice lacking IRS-3 do not show defects in growth and metabolism [14]. IRS-4 also seems not to play an important role in these processes because mice without IRS-4 manifest only mild defects in growth, glucose homeostasis and reproduction [15]. These functional differences between IRSs first derive from their specific patterns of tissue expression. Although the expression of IRS-1 and IRS2 is ubiquitous, IRS-3 and IRS-4 are expressed in limited tissues and organs $[1,2,7,16,17]$. Secondly, each member of the IRS family has a distinct pattern of association with various $\mathrm{SH} 2$ domain-containing proteins in response to insulin $[7,8,18,19]$. Thirdly, the intracellular localization of IRSs is different because IRS-1 and IRS- 2 associate with an intracellular structure containing cytoskeleton whereas IRS-3 and IRS4 are targeted to the plasma membrane both in the presence and absence of insulin [19-22]. However, the molecular mechanisms of these functional differences between IRSs have not been analysed in detail.

In the analysis of IRS-1 null mice, we have shown that insulin signalling and biological actions were impaired in muscles from IRS-1 null mice which was in contrast to the grossly normal signalling and actions in livers from these mice [23]. The difference in the degree of insulin resistance in these two major insulin targets from IRS-1 null mice seemed to depend on the amount of tyrosine phosphorylation of IRS-2 because tyrosine phosphorylation of IRS- 2 in livers from these mice was enhanced whereas in their muscles it was much less. In contrast, in primary adipocytes from IRS-1 null mice, tyrosine phosphorylation of pp60/IRS-3 was comparable to that of IRS-1 in adipocytes from wild-type mice, although pp60/IRS-3 in adipocytes from IRS-1 null mice incompletely com- pensated for the absence of IRS-1 in mediating insulin-stimulated PI 3-kinase activity and glucose transport [24]. Therefore, different from IRS-2, these data indicated that IRS-3 could play a minor role in transmitting insulin signal even if its expression was comparable to IRS-1. To analyse the functional difference between IRS-1 and IRS-3, we transiently expressed rat IRS-1, IRS-3, or chimeric proteins of these two IRSs in Cos- 1 cells and examined the tyrosine phosphorylation via the wild-type or mutant insulin receptors. In addition, we evaluated the targeting of IRS-1, IRS-3 or the chimeric proteins to the plasma membrane in the presence or absence of insulin by immunostaining the membrane ghost and confocal microscopy.

\section{Materials and methods}

Materials. Mouse monoclonal $4 \mathrm{G} 10$ antibody (specific for phosphotyrosine: $\alpha \mathrm{PY}$ ) was purchased from Upstate Biotechnology (Lake Placid, USA). Rabbit polyclonal antibodies against haemagglutinin ( $\alpha \mathrm{HA})$ were purchased from Santa Cruz Biotechnology (Calif., USA). Rabbit polyclonal antibodies against the $\beta$ subunit of human insulin receptor $(\alpha \operatorname{IR} \beta)$ were obtained from Transduction Laboratories (Lexington, USA). The CellPhect transfection kit (Amersham Pharmacia Biotech, Buckinghamshire, UK), BM chemiluminescence Western blotting kit (Boehringer Mannheim, Germany), 25$\mathrm{mm}$ diameter circular glass coverslips (Iwaki, Tokyo, Japan), an ultrasonic microprobe (Branson Sonifier Model 250), fluorescein isothiocyanate (FITC)-conjugated goat antibody against rabbit IgG (Chemicon, Calif., USA), tetramethyl rhodamine isothiocyanate (TRITC)-conjugated phalloidin (Sigma, St Louis, Mo., USA), wortmannin (Sigma) and 4', 6-diamine-2'-phenylindole dihydrochloride (DAPI; Sigma) were also used in this study.

Site-directed mutagenesis and construction of expression vectors. The pcDNA3 vector containing the rat IRS-3 cDNA (nucleotides 93-1670) [3] with the C-terminal HA tag (pcDNA3IRS3) was described previously [9]. Using polymerase chain reaction as described $[25,26]$, the HA tag was inserted into the Cterminus of rat IRS-1 (nucleotides 587-4293) and an expression vector containing this cDNA [1,27] was constructed (pcDNA3IRS1). Utilizing pcDNA3-IRS1 and pcDNA3-IRS3 as the templates, the expression vectors containing various IRS-1 - IRS-3 chimeric cDNAs were constructed (Fig. 1). The expression vectors containing IRS- 3 cDNAs with the deletion of the PH domain or the PTB domain were also made (Fig. 1).

Expression of wild-type and mutant IRS proteins with the human insulin receptor. Subconfluent Cos-1 cells in 6-cm dishes were transfected with $3 \mu \mathrm{g} /$ dish (or the indicated amount) of plasmid containing the wild-type or mutant IRS cDNA and $3 \mu \mathrm{g} /$ dish of the wild-type (Ullrich-type) [28, 29] or mutant human insulin receptor expression vector [29] by calcium phosphate precipitation using the CellPhect transfection kit. After $24 \mathrm{~h}$, the transfected cells were incubated in serum-free medium for 12 to $16 \mathrm{~h}$ and subjected to the experiments described below.

Immunoblotting of phosphotyrosine-containing proteins with $\alpha P Y$. Assays were done as described [29]. Briefly, Cos-1 cells 


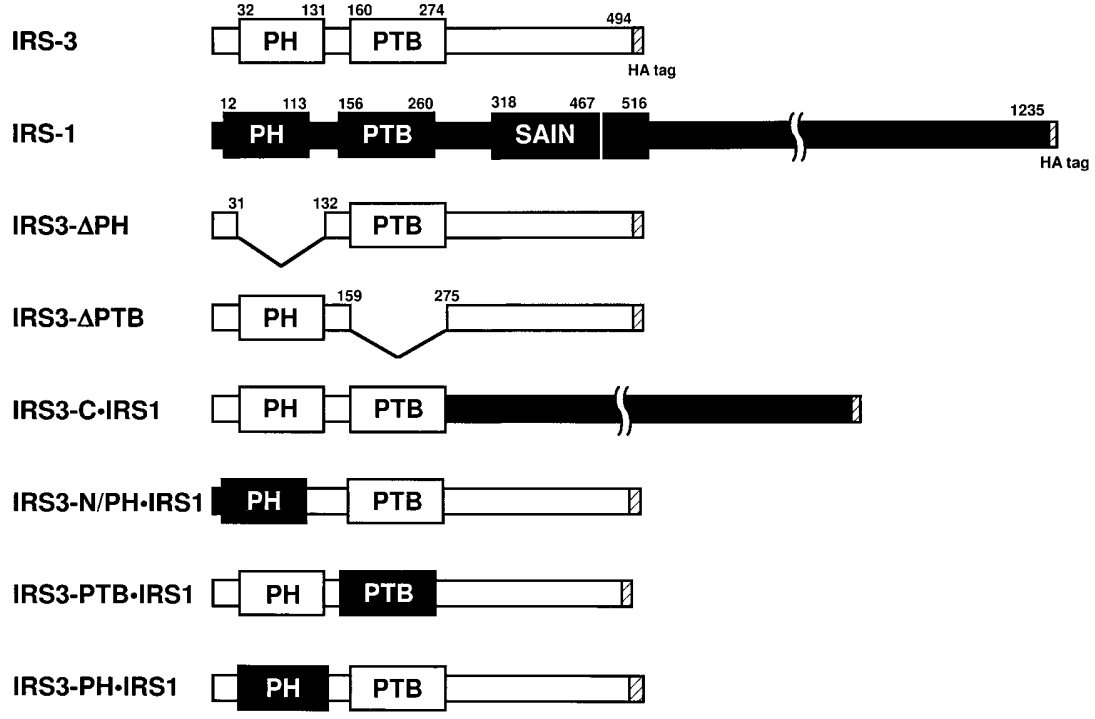

Fig. 1. The generated structures of IRS mutant proteins. Utilizing the cDNAs of rat IRS-1 and IRS-3 as templates, the expression vectors containing IRS-1/IRS-3 chimeric cDNAs were generated by PCR. The expression vectors containing IRS-3 cDNAs with the deletion of the PH domain or the PTB domain were also made. The structures of IRS mutant proteins are shown

treated or untreated with $10^{-7} \mathrm{~mol} / 1$ insulin for $1 \mathrm{~min}$ at $37^{\circ} \mathrm{C}$ were lysed in buffer A ( $25 \mathrm{mmol} / \mathrm{l}$ Tris-HCl; $\mathrm{pH} 7.4,2 \mathrm{mmol} / \mathrm{l}$ sodium orthovanadate, $10 \mathrm{mmol} / \mathrm{l} \mathrm{NaF}, 10 \mathrm{mmol} / \mathrm{l}$ sodium pyrophosphate, $1 \mathrm{mmol} / \mathrm{l}$ phenylmethylsulfonyl fluoride, $1 \mathrm{mmol} / \mathrm{l} \mathrm{EGTA}$, and $1 \mathrm{mmol} / \mathrm{l}$ EDTA) containing $1 \%$ Triton $\mathrm{X}-100$. Cell lysates containing equal amounts of protein (approximately $4 \mathrm{mg} / \mathrm{sample}$ ) were immunoprecipitated with antibodies, subjected to SDS-PAGE followed by western blotting with $\alpha \mathrm{PY}$ and visualized using chemiluminescence detection. The amount of tyrosine-phosphorylated IRS was evaluated by densitometry and expressed as the percentage of IRS-3 tyrosine phosphorylation in Cos- 1 cells coexpressing the wildtype insulin receptor and IRS-3. To confirm that comparable amount of proteins were expressed, equal amounts of total lysates were subjected to SDS-PAGE followed by western blotting with $\alpha \mathrm{HA}$ or $\alpha \operatorname{IR} \beta$.

Detection of IRS proteins associated with the plasma membrane by confocal microscopy. For immunostaining, Cos-1 cells plated onto 25 -mm diameter circular glass coverslips were serumstarved for $12 \mathrm{~h}$, and treated or untreated with $10^{-7} \mathrm{~mol} / \mathrm{l}$ insulin for $5 \mathrm{~min}$ at $37^{\circ} \mathrm{C}$. To examine the inhibition of insulin-induced IRS targeting to the plasma membrane (PM) by PI 3-kinase inhibitor wortmannin [30], cells were preincubated with or without $100 \mathrm{nmol} / \mathrm{l}$ wortmannin for $30 \mathrm{~min}$ before insulin stimulation. PM lawns from these cells were generated as described [31] with several modifications. Insulin-stimulated or insulin-unstimulated coverslips were washed with ice-cold phosphate buffered saline (PBS), followed by a 10-s treatment with PBS containing $0.5 \mathrm{mg} / \mathrm{ml}$ polylysine. The cells were incubated for $5 \mathrm{~s}$ in a hypotonic buffer $(1 / 3 \cdot$ buffer B), transferred to buffer $\mathrm{B}(70 \mathrm{mmol} / \mathrm{l} \mathrm{KCl}, 30 \mathrm{mmol} / \mathrm{l}$ HEPES, $5 \mathrm{mmol} / \mathrm{l}$ $\mathrm{MgCl}_{2}, 3 \mathrm{mmol} / \mathrm{l}$ EGTA; pH 7.3), immediately broken open by placing under an ultrasonic microprobe, and transferred to $4 \%$ paraformaldehyde in buffer B. For immunostaining IRS proteins, coverslips were incubated with $\alpha \mathrm{HA}$ at $4{ }^{\circ} \mathrm{C}$ overnight, washed and incubated with FITC-conjugated goat antibody against rabbit IgG and TRITC-conjugated phalloidin. The stained sections were mounted in a paraphenylene diamine and glycerol solution [32] and the PM lawns were visualized and imaged using a scanning laser confocal immunofluorescence microscope (Olympus, Tokyo, Japan). As DAPI and TRITC staining revealed the absence of nuclei and the preservation of submembranous actin filaments, almost all the cell contents were considered to be removed leaving behind uniform PM lawns. Lawns from transfected cells were selected by staining with $\alpha \mathrm{HA}$, and at least 10 cells were evaluated in each experiment.

Statistical analysis. Where appropriate, data were expressed as the means and standard errors of three independent experiments. Statistical significance was assessed using the Student's $t$ test. A $p$ value of less than 0.05 was considered statistically significant.

\section{Results}

Insulin-induced tyrosine phosphorylation of IRS proteins in Cos-1 cells expressing mutant insulin receptors. We previously examined tyrosine phosphorylation of IRS-1 in CHO cells expressing mutant insulin receptors and verified that the juxtamembrane region of the receptor including $\mathrm{Tyr}^{960}$ is required for normal tyrosine phosphorylation of IRS-1 [29,33]. To analyse insulin-stimulated tyrosine phosphorylation of IRS-3, the cell lysates from Cos- 1 cells transiently coexpressing insulin receptors and IRS-1 or IRS-3 were immunoprecipitated with $\alpha \mathrm{HA}$, subjected to SDS-PAGE followed by immunoblotting with $\alpha \mathrm{PY}$. As previously reported [29,34], the Y960F insulin receptor impaired tyrosine phosphorylation of IRS-1 to $4.9 \pm 0.9 \%$ of wild-type insulin receptor $(p<0.01)$ (Fig. 2A, lanes $1-4)$. In contrast, the Y960F insulin receptor did not significantly decrease tyrosine-phosphorylation of IRS-3 $(95.5 \pm 23.8 \%$ of wild-type insulin receptor $)$ 


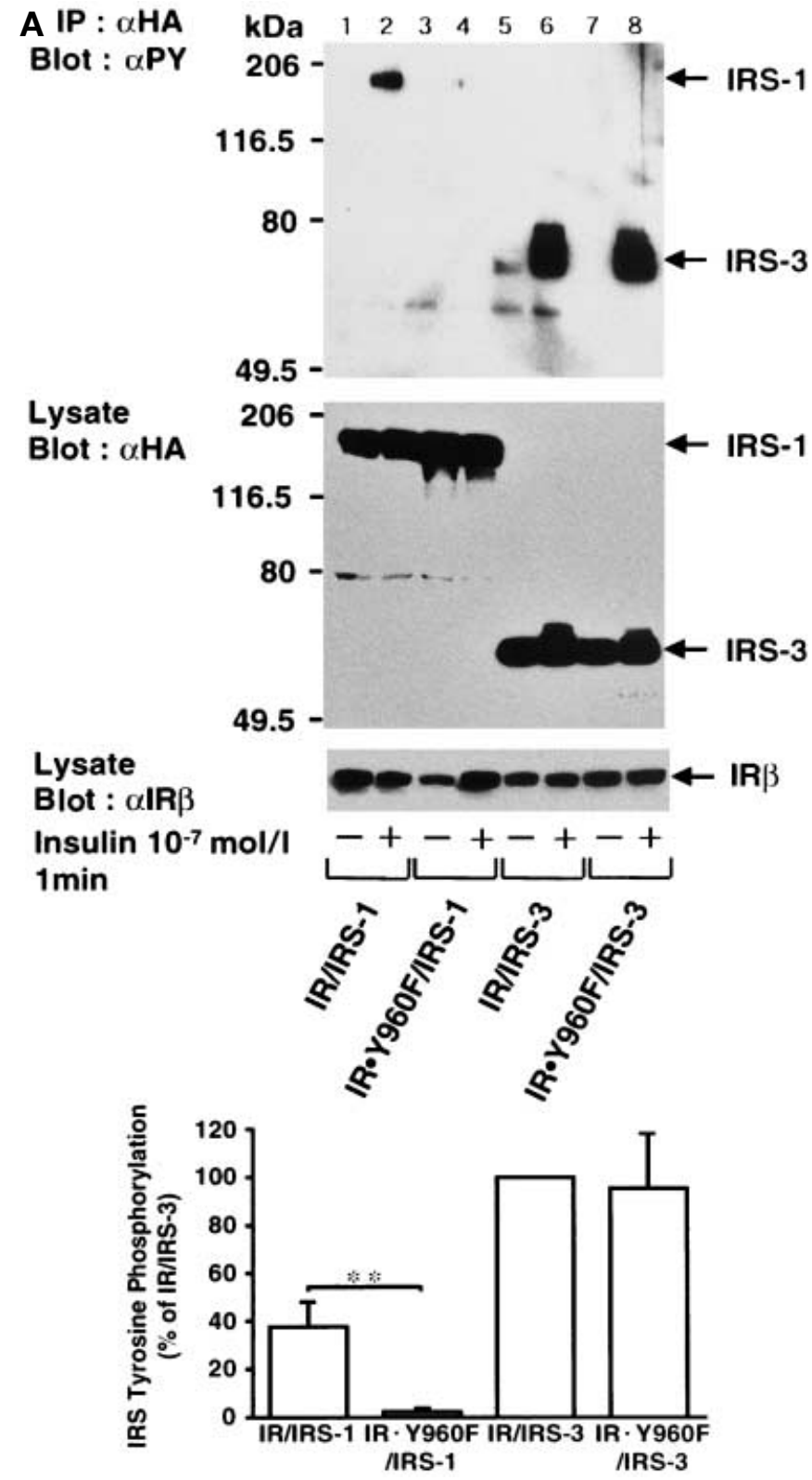

Fig. 2 A, B. Insulin-induced tyrosine phosphorylation of IRS-1 and IRS-3 in Cos- 1 cells coexpressing wild-type or mutant insulin receptors and IRSs. (A) Tyrosine-phosphorylation of IRS-1 and IRS-3 in Cos-1 cells expressing the wild-type or Y960F insulin receptors. (B) IRS-3 tyrosine phosphorylation in Cos-1 cells expressing the wild-type or Y960F insulin receptors and different protein levels of IRS-3. After treatment with $10^{-7} \mathrm{~mol} / 1$ insulin for $1 \mathrm{~min}$, total lysates from Cos- 1 cells expressing wild-type or mutant insulin receptors with IRS-1 or IRS-3 were immunoprecipitated with $\alpha \mathrm{HA}$, subjected to SDS-polyacrylamide gel electrophoresis followed by immunoblotting with $\alpha \mathrm{PY}$, as described in "Materials and methods". To confirm that comparable amount of proteins were expressed, total lysates were subjected to SDS-PAGE followed by western blotting with $\alpha \mathrm{HA}$ or $\alpha \operatorname{IR} \beta$. The bands corresponding to IRS- 1 , IRS- 3 and the $\beta$ subunit of insulin receptor (IR $\beta$ ) are indicated. The amount of tyrosine-phosphorylated IRSs was evaluated by densitometry and expressed as the percentage of IRS- 3 tyrosine phosphorylation in Cos- 1 cells expressing the wild-type insulin receptor and IRS-3. The data are the means and standard errors of three independent experiments. $* * p<0.01$ vs control
B
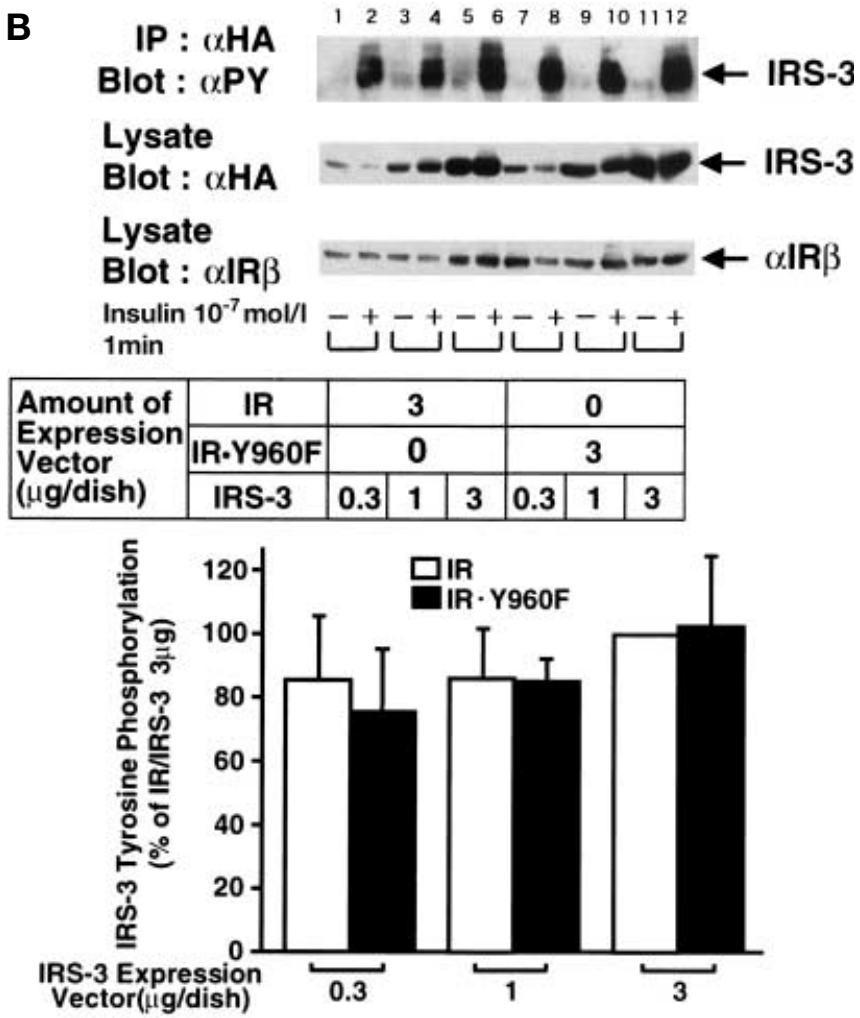

(Fig. 2A, lanes 5-8). In vitro binding and two-hybrid analyses have previously verified the interaction of both IRS-1 and IRS-3 through their PTB domains with the NPXpY motif of the insulin receptor [3539], which has been believed to be essential for the efficient tyrosine phosphorylation of IRSs. The results shown in Fig. 2 A clearly show that different from IRS-1, IRS-3 appears to be tyrosine-phosphorylated by a mechanism independent of the interaction between the PTB domain of IRS-3 and the juxtamembrane NPXpY motif of the insulin receptor. To exclude the possibility that high expression of IRS-3 permitted its access to the insulin receptor without requiring a specific interaction through $\mathrm{Tyr}^{960}$ of the insulin receptor, we analysed tyrosine phosphorylation of IRS-3 via the wild-type or Y960F insulin receptor in Cos-1 cells transfected with a low amount of the IRS-3 expression vector ( 0.3 and 1 vs. $3 \mu \mathrm{g} / \mathrm{dish})$. As shown in Fig. 2B, low expression of IRS-3 caused no difference in tyrosine phosphorylation of IRS-3 between the cells expressing the wild-type and Y960F insulin receptors. These data indicate that in IRS-3 there exists a mechanism which facilitates signal transmission even in the absence of the juxtamembrane $\mathrm{Tyr}^{960}$ of the insulin receptor.

The PH and PTB domains of IRS-3, as well as the juxtamembrane region of the insulin receptor, is essential for tyrosine phosphorylation in response to insulin. To examine the reason why IRS-3 was tyrosinephosphorylated by the Y960F insulin receptor com- 
A
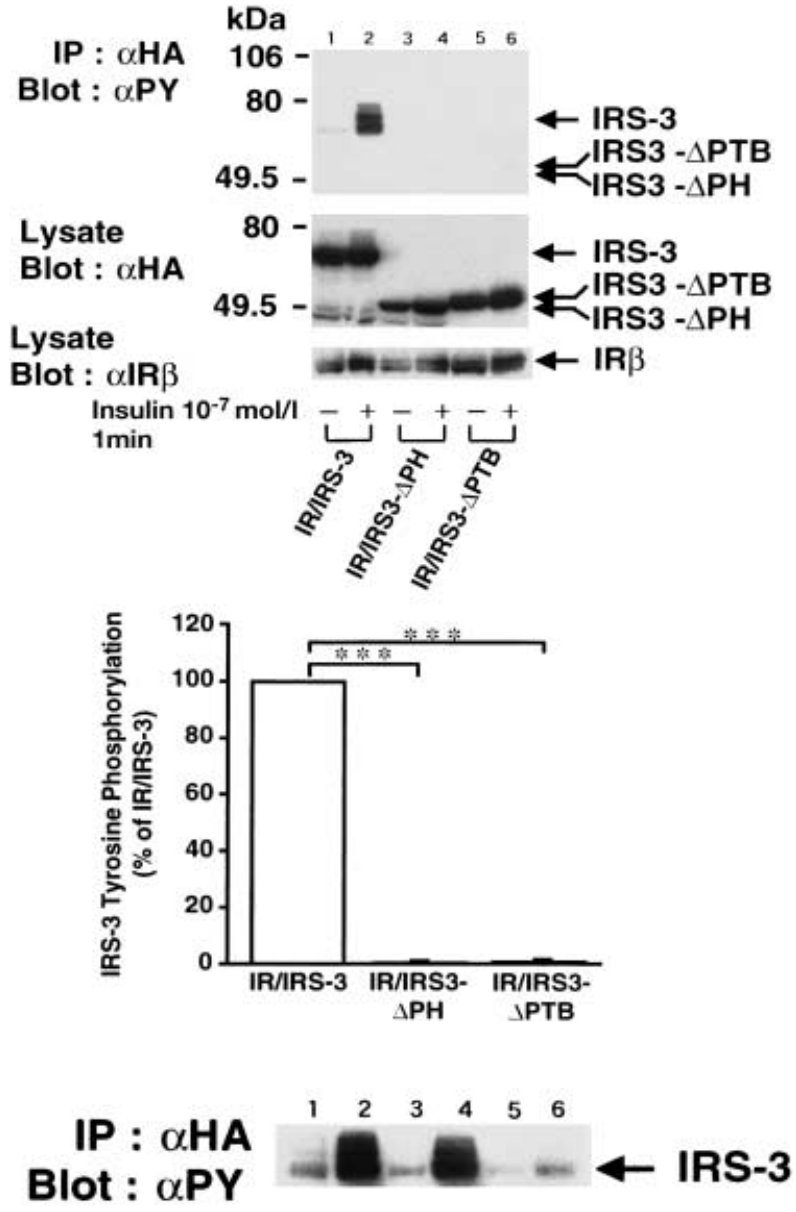

Lysate

Blot : $\alpha$ HA

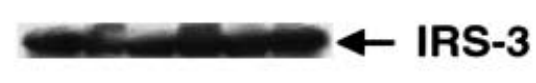

Lysate

Blot : $\alpha \mathrm{IR} \beta$

${ }_{\text {Imin }}^{\text {Insulin } 10^{-7} \mathrm{~mol} / \mathrm{l}}$

B

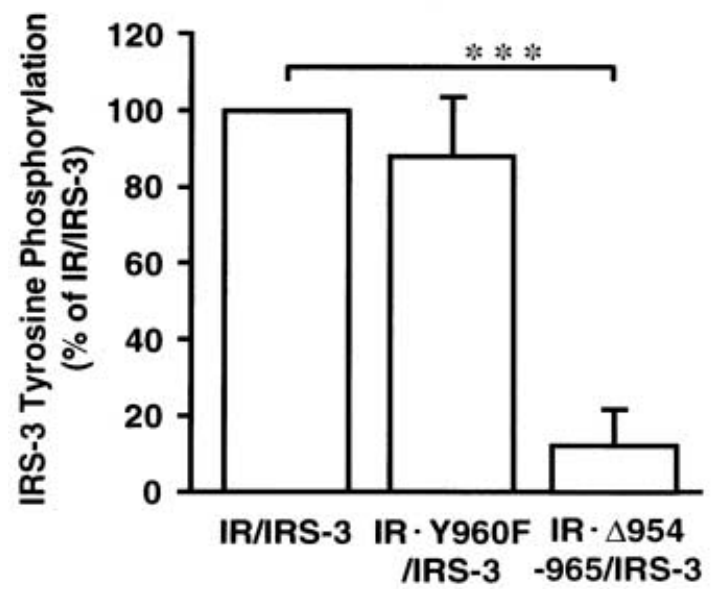

Fig.3 A, B. Insulin-induced tyrosine phosphorylation of IRS-3 requires both the PH and PTB domains of IRS-3 as well as the juxtamembrane region of the insulin receptor. (A) Tyrosinephosphorylation of IRS-3 with its PH or PTB domain in Cos1 cells expressing the wild-type insulin receptors. (B) IRS-3 tyrosine phosphorylation in Cos-1 cells expressing the wild-type, Y960F or $\Delta 954-965$ insulin receptors. After treatment with $10^{-7} \mathrm{~mol} / \mathrm{l}$ insulin for $1 \mathrm{~min}$, total cell lysates were immunoprecipitated with $\alpha \mathrm{HA}$, subjected to SDS-polyacrylamide gel electrophoresis followed by immunoblotting with $\alpha \mathrm{PY}$, as described in Materials and methods. To confirm that a comparable amount of protein was expressed, total lysates were subjected to SDS-PAGE followed by western blotting with $\alpha \mathrm{HA}$ or $\alpha \operatorname{IR} \beta$. The amount of tyrosine-phosphorylated IRS-3 was evaluated by densitometry and expressed as the percentage of IRS-3 tyrosine phosphorylation in Cos- 1 cells expressing the wild-type insulin receptor and IRS-3. The data are the means and standard errors of three independent experiments. $* * * p<0.001$ vs control

parable to the wild-type receptor, we first analysed the roles of the PH and PTB domains of IRS-3 by introducing deletions into these regions because both these domains have been shown to be essential for insulin-stimulated tyrosine phosphorylation of IRS-1 [35-38, 40-42] (Figs. 1 and 3A). As reported [39], the deletion of the $\mathrm{PH}$ domain of IRS-3 $(0.15 \pm 0.27 \%$ of wild-type, $p<0.001)$ (Fig. 3A, lanes $3-4)$, as well as the PTB domain deletion $(0.28 \pm 0.49 \%$ of wild-type, $p<0.001)$ (Fig. 3A, lanes 5-6), significantly impaired tyrosine phosphorylation of IRS-3 in Cos-1 cells expressing the wild-type insulin receptor. Second, we assessed whether the deletion of the juxtamembrane residues 954-965 of the insulin receptor $($ IR・ $\triangle 954-965)$ [29], which has been shown to abolish tyrosine phosphorylation of IRS-1 [43], impairs tyrosine phosphorylation of IRS-3 (Fig. 3B). We observed a decrease in tyrosine phosphorylation of IRS-3 through the IR• $\triangle 954-965$ insulin receptor $(11.9 \pm 8.9 \%$ of wild-type, $p<0.001)$ (Fig. 3B, lanes 5-6) whereas no significant decrease in IRS-3 tyrosine phosphorylation was seen in the cells expressing the Y960F cells $(88.5 \pm 15.3 \%$ of wild-type) (lanes 3-4). These deletion experiments show that although IRS-3 transmits signals from the insulin receptor in a manner different from IRS-1, the presence of both the PH domain and the PTB domain of IRS-3 as well as the juxtamembrane region of the insulin receptor is essential for insulin-stimulated tyrosine phosphorylation of IRS-3 in response to insulin.

The PH but not the PTB, domain of IRS-3 is required for its normal tyrosine phosphorylation in Cos-1 cells expressing the Y960F insulin receptors. To evaluate precisely the difference between IRS-1 and IRS-3 in transmitting signals from the insulin receptor, we generated several expression vectors containing cDNAs 


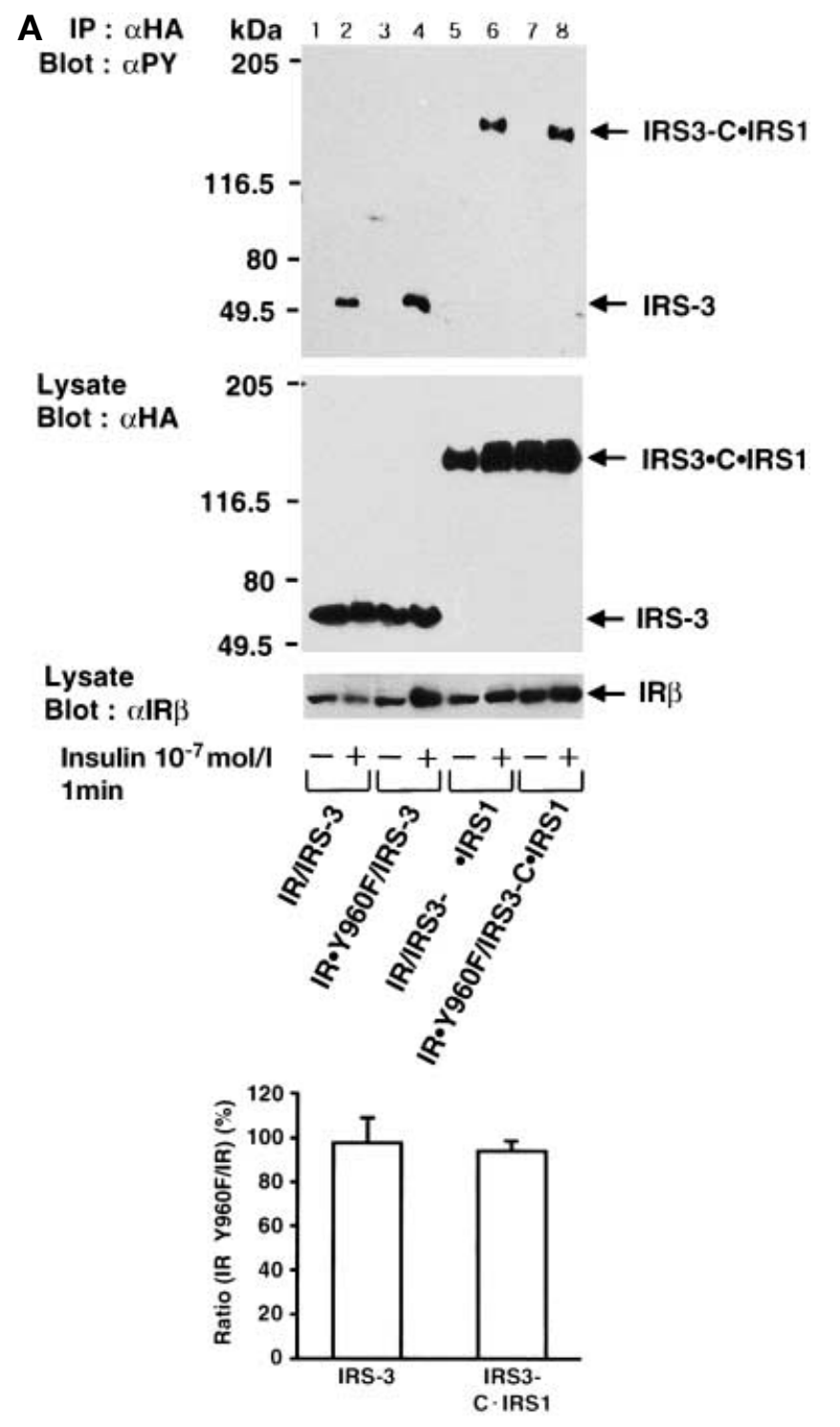

Fig. 4a-c. Insulin-induced tyrosine phosphorylation of IRS-3 or chimeric proteins in Cos-1 cells expressing wild-type or mutant (Y960F) insulin receptors. After treatment with $10^{-7} \mathrm{~mol} / 1$ insulin for $1 \mathrm{~min}$, total lysates from Cos-1 cells expressing IRSs and chimeric proteins (A) IRS3-C•IRS1, (B) IRS3-N/ $\mathrm{PH} \bullet \mathrm{IRS} 1$ and IRS3-PTB・IRS1, (C) IRS3-PH・IRS1) with wild-type or Y960F insulin receptors were subjected to SDSpolyacrylamide gel electrophoresis followed by immunoblotting with $\alpha \mathrm{HA}$, as described in "Materials and methods". To confirm that comparable amount of proteins were expressed, total lysates were subjected to SDS-PAGE followed by western blotting with $\alpha \mathrm{HA}$ or $\alpha \operatorname{IR} \beta$. The ratio of the extent of the tyrosine phosphorylation of each chimeric protein in the cells expressing the Y960F insulin receptors to that in the cells expressing the wild-type insulin receptors were calculated and compared with that of IRS-3. The data are the means and standard errors of three independent experiments. * $p<0.05$ vs control; $* * p<0.01$ vs control; $* * * p<0.001$ vs control
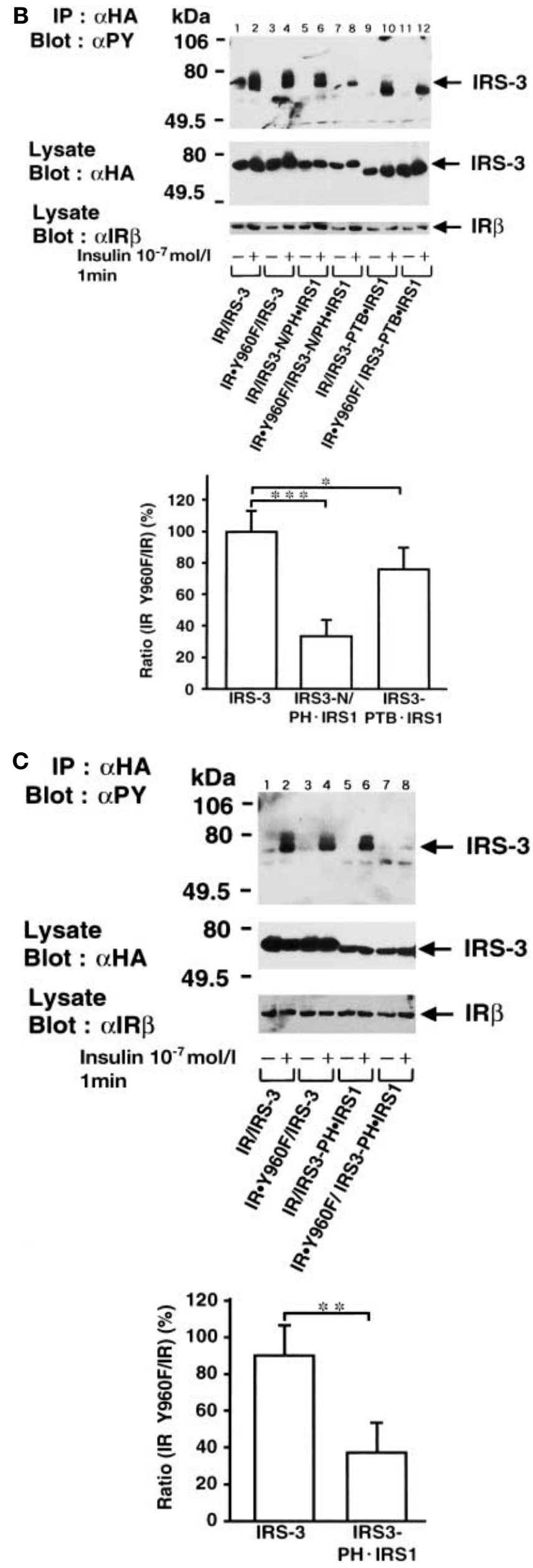


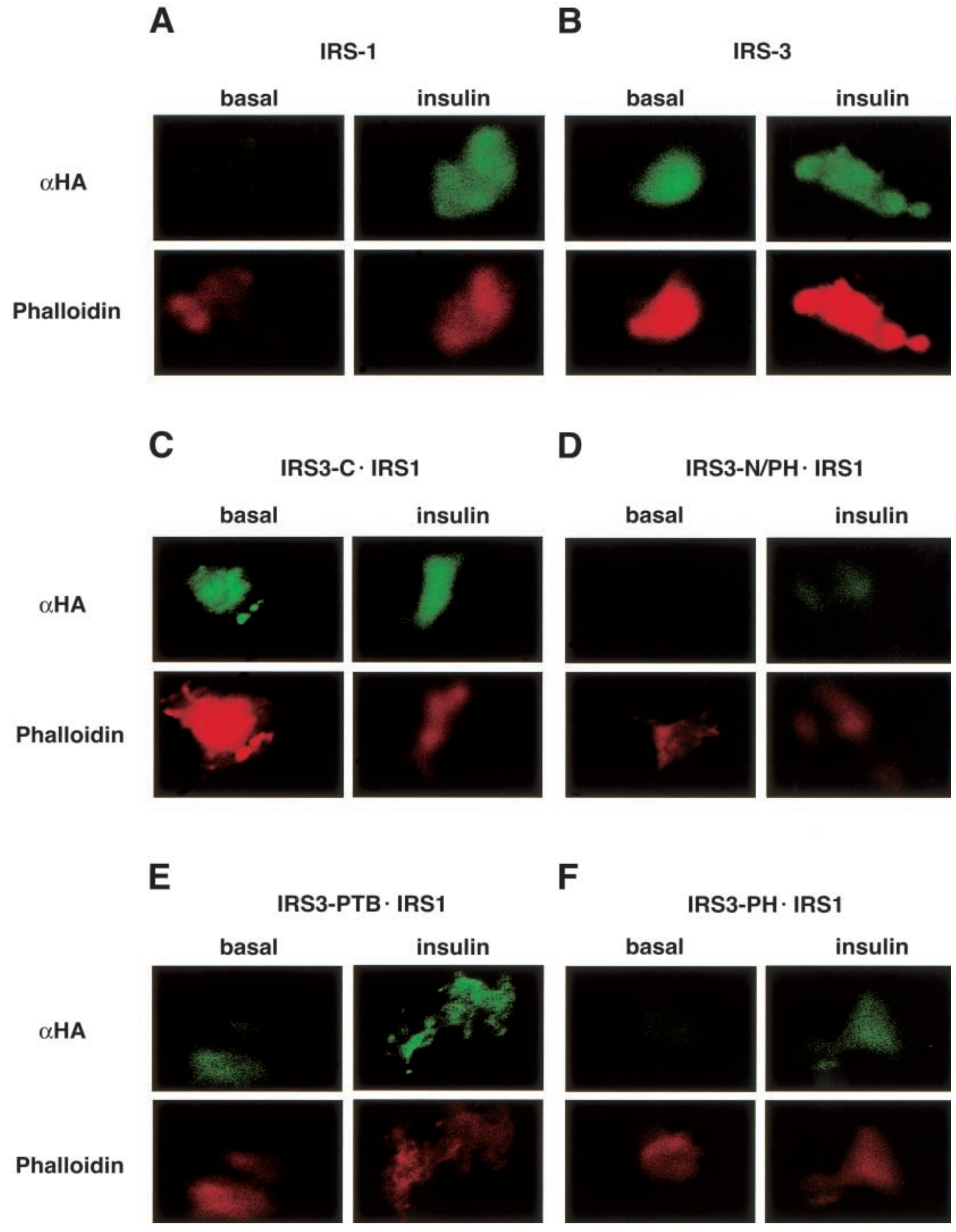


Fig. 5. Detection of IRS proteins associated with the plasma membrane by confocal microscopy. After Cos- 1 cells plated onto $25-\mathrm{mm}$ diameter circular glass coverslips were stimulated with $10^{-7} \mathrm{~mol} / \mathrm{l}$ insulin for $5 \mathrm{~min}$, the cells were fixed and sonicated to obtain membrane ghosts. IRS-1 (A), IRS-3 (B), IRS3-C•IRS1 (C), IRS3-N/PH・IRS1 (D), IRS3PTB・IRS1 (E), or IRS3-PH•IRS1 (F) bound to the plasma membrane were visualized by immunostaining with $\alpha \mathrm{HA}$ and confocal microscopy, as described in Materials and methods. Phalloidin labelling among individual plasma membrane fragments was also shown to confirm that the structures of the plasma membrane were preserved in this procedure

of chimeric proteins changing the domains of IRS-3 to the corresponding moieties of IRS-1 (Fig.1). As the density of the band from each chimeric protein in $\alpha$ PY immunoblotting was different, we calculated in each chimeric protein the ratio of its tyrosine phosphorylation in the cells expressing the Y960F insulin receptors to that in the cells expressing the wild-type insulin receptors and compared the ratio with that of IRS-3.

As the C-terminal region of IRS-1 contains the SAIN domain (human: residues 313-462, rat: residues 318-467) which directly interacts with the insulin receptor [42], the C-terminal region of IRS-3 was replaced with that of IRS-1 which does not include the SAIN domain and its adjacent 50 amino acids of IRS-1 in IRS3-C•IRS1 (Fig. 1). The alteration of the C-terminal region of IRS-3 to that of IRS-1 (IRS3C•IRS1) did not have a significant decrease in tyrosine phosphorylation of the chimeric protein in Cos-1 cells expressing the Y960F insulin receptor $(93.2 \pm 14.3 \%)$ (Fig. 4A, lanes 5-8), suggesting that the C-terminus of IRS-3 is not involved in the receptor $\mathrm{Tyr}^{960}$-independent tyrosine phosphorylation of IRS-3. Therefore, IRS-3 appears to be tyrosine-phosphorylated by the Y960F insulin receptor in a mechanism distinct from IRS-2, the RBD2 domain which is responsible for the direct interaction of this molecule with the insulin receptor leading to its efficient tyrosine phosphorylation in cells expressing the Y960F insulin receptor [44, 45].

Although the PH domain is considered to be involved in the interaction with phospholipids but not with the insulin receptor, the replacement of the $\mathrm{N}$ terminal region containing the PH domain of IRS-3 with that of IRS-1 (IRS3-N/PH•IRS1) impaired tyrosine phosphorylation of the chimeric protein via the Y960F insulin receptor $(32.8 \pm 11.4 \%, p<0.001)$ (Fig. 4B, lanes 5-8). The alteration of the $\mathrm{PH}$ domain alone (IRS3-PH• - IRS1) (Fig. 4C, lanes 5-8) also decreased tyrosine phosphorylation of the chimera mediated by the Y960F insulin receptor $(37.6 \pm 15.1 \%$, $p<0.01)$. In addition, the replacement of the PTB domain of IRS-3 with that of IRS-1 (IRS3PTB• IRS1) showed a mild but significant decrease in tyrosine phosphorylation of the chimeric protein mediated by the Y960F insulin receptor $(77.1 \pm 12.9 \%, p<0.05)$ (Fig. 4B, lanes 9-12). These data suggest that the PH domain of IRS-3 plays a distinct role from that of IRS- 1 in insulin-induced tyrosine phosphorylation of IRS-3 via the Y960F insulin receptor and that the PTB domain of IRS-3 is also partially involved in this process.

The PH domain of IRS-3 is critical for insulin-independent localization of IRS-3 to the plasma membrane. The PH domain of IRS-1 plays a role in localizing this molecule to the plasma membrane, an important step for its subsequent interaction with the insulin receptor [40-42]. To evaluate whether efficient tyrosine phosphorylation of IRS-3 via the Y960F insulin receptor is due to the different subcellular distribution of IRS-3 from that of IRS-1, we examined the localization of IRS-1 and IRS-3 to the plasma membrane in the presence or absence of insulin by immunostaining the membrane ghost with $\alpha \mathrm{HA}$ followed by confocal microscopy. The representative lawns from unstimulated or insulin-stimulated cells which were labelled with antibodies specific for HA and phalloidin are shown (Fig. 5). The uniformity of phalloidin labelling indicated that submembranous actin filaments as well as the structures of plasma membranes were preserved. Although plasma membranes from unstimulated cells expressing HA-tagged IRS1 had very low IRS-1 labelling, insulin increased the staining intensity of HA-tagged IRS-1 (Fig. 5A). In contrast to IRS-1, IRS-3 was localized to the plasma membrane even in the absence of insulin and the insulin treatment did not seem to change its distribution (Fig. 5B). To determine which domains in IRS-1 and IRS-3 mediate the different localization of these molecules, the localization of chimeric proteins in which various domains of IRS-3 were replaced with the corresponding domain of IRS-1 was examined in an unstimulated or insulin-stimulated state. The replacement of the C-terminal region of IRS-3 with that of IRS-1 (IRS3-C• IRS1) did not affect the distribution of the chimeric protein as compared with that of IRS-3 (Fig. 5C). The PTB domain of IRS-3 to that of IRS-1 (IRS3-PTB・IRS1) also failed to change the localization of the chimeric protein as compared with that of IRS-3 (Fig. 5E). In contrast, changes in the region containing the $\mathrm{PH}$ domain of IRS-3 to that of IRS-1 (IRS3-N/PH• IRS1 and IRS3$\mathrm{PH} \bullet \mathrm{IRS} 1)$ reduced the targeting of the chimeric proteins to the plasma membrane in the basal state, and insulin increased the staining intensity of the chimeric proteins similar to that of IRS-1 (Figs. 5, D and F). These results suggest that, especially in the basal state, the affinity of the PH domain of IRS-3 for the plasma membrane is markedly stronger than that of IRS-1, which could explain why IRS-3 is tyrosinephosphorylated in intact cells via the Y960F insulin 
A

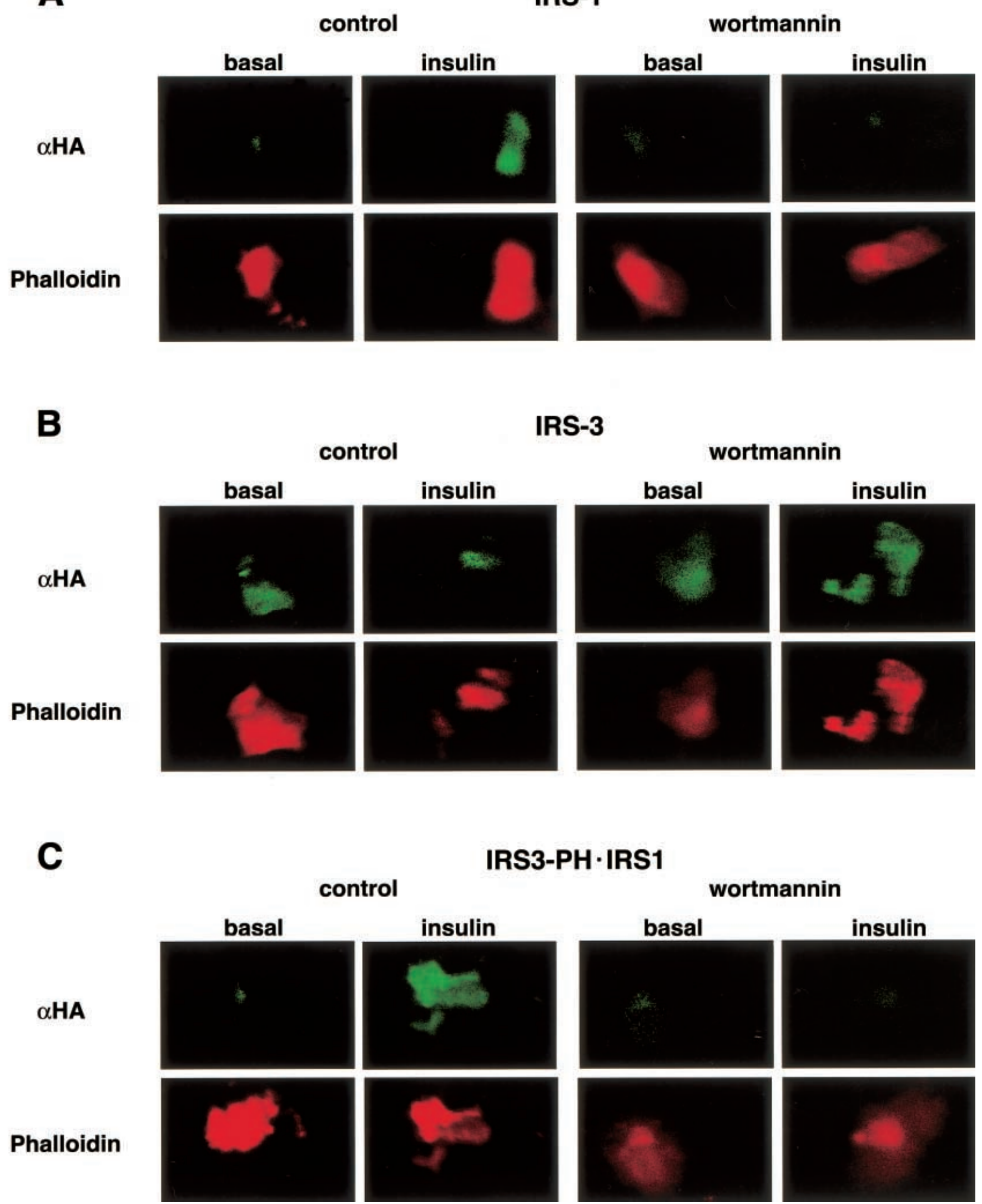


Fig. 6. Influence of wortmannin treatment on insulin-unstimulated and insulin-stimulated targeting of IRSs to the plasma membrane.

After Cos-1 cells were treated or untreated with $100 \mathrm{nmol} / \mathrm{l}$ wortmannin for $30 \mathrm{~min}$, the cells were stimulated with $10^{-7}$ $\mathrm{mol} / \mathrm{l}$ insulin for $5 \mathrm{~min}$, fixed and sonicated to obtain membrane ghosts. IRS-1 (A), IRS-3 (B), IRS3-PH • IRS1 (C) bound to the plasma membrane were visualized by immunostaining with $\alpha \mathrm{HA}$ and confocal microscopy. Phalloidin labelling among individual plasma membrane fragments was also shown to confirm that the structures of plasma membrane were preserved in this procedure

receptor to the extent comparable to the wild-type insulin receptor.

Wortmannin blocks insulin-induced localization of IRS-1 but not IRS-3 to the plasma membrane. It has been recently suggested that $\mathrm{PI}(3,4,5) \mathrm{P}_{3}$ and $\mathrm{PI}(4,5) \mathrm{P}_{2}$ could be the ligands for the $\mathrm{PH}$ domain of IRS- 1 and that in unstimulated cells IRS- 1 associates with $\mathrm{PI}(4,5) \mathrm{P}_{2}$ contained in the plasma membrane, whereas insulin stimulation leads to the accumulation of $\mathrm{PI}(3,4,5) \mathrm{P}_{3}$ which causes the translocation of IRS1 to the plasma membrane thereby transiently fixing the receptor and substrate [46]. To test whether the constitutive localization of IRS-3 to the plasma membrane via its $\mathrm{PH}$ domain was $\mathrm{PI}(3,4,5) \mathrm{P}_{3}$-dependent we examined the influence of treatment with wortmannin, a PI 3-kinase inhibitor [30], on the localization of IRS-1, IRS-3, or the chimeric protein with the PH domain alteration (IRS3-PH• IRS1) (Fig. 6). Insulin-stimulated targeting of IRS- 1 to the plasma membrane was suppressed by wortmannin, although plasma membranes from insulin-stimulated and wortmannin-stimulated cells still preserved low IRS-1 labelling comparable to that from unstimulated cells (Fig. 6A). In contrast, wortmannin did not affect the distribution of IRS-3 in both unstimulated and insulin-stimulated cells (Fig. 6B). The replacement of the PH domain of IRS-3 with that of IRS-1 (IRS3$\mathrm{PH} \bullet$ IRS1) changed the distribution of the chimeric protein to the IRS-1-like pattern (Fig. 6C). These results suggest that IRS-3 is localized to the plasma membrane via its PH domain binding to PI 3-kinaseindependent phospholipids or other ligands, whereas the interaction of the PH domain of IRS-1 with the enzyme-regulated phosphoinositides plays a major role in insulin-stimulated targeting of IRS- 1 to the plasma membrane. In addition, the preservation of IRS-1 in plasma membranes from insulin-stimulated and wortmannin-stimulated cells comparable to that from unstimulated cells (Fig. 6A) suggests that PI 3kinase-unregulated phosphoinositides or other molecules play a role in the localization of IRS- 1 in a basal state.

\section{Discussion}

We showed that the PH domain of IRS-3 plays a major role in the tyrosine phosphorylation of IRS-3 in a receptor NPXpY motif-independent fashion. Using the immunostaining analysis, we also showed that in contrast to the wortmannin-sensitive accumulation of IRS-1 to the plasma membrane in response to insulin, IRS-3 was localized to the plasma membrane in an insulin-independent and wortmannin-resistant manner. Among the endogenous substrates of the insulin receptor tyrosine kinase, Gab1 contains the $\mathrm{PH}$ domain but not the PTB domain or any other domain in its N-terminus which interacts with the insulin receptor [5, 47]. Using an in vivo assay in yeast, the association of the PH domain of Gab1, but not that of IRS-1, with the PI 3-kinase products was detected [48]. Since only high-affinity binding $(\mathrm{Kd}$ of $<1$ $\mu \mathrm{mol} / \mathrm{l})$ to phosphoinositides could be detected in their system [48], these data suggest that high-affinity binding of the $\mathrm{PH}$ domain of Gab1 to $\mathrm{PI}(3,4,5) \mathrm{P}_{3}$ enables tyrosine phosphorylation of Gab1 even in the absence of the domains that directly associate with the activated receptor. In contrast, as the interaction between the PH domain of IRS-1 and the phosphoinositides or other ligands in the plasma membrane seems to be weak $[46,48]$, the cooperation of the PTB domain interacting with the insulin receptor could be required for efficient tyrosine phosphorylation of IRS-1 as well as other members of the IRS family. From our data we could deduce that the extent of the interaction between the IRSs and the insulin receptor, which is required for transducing signals from the insulin receptor, could be influenced by the affinity of the $\mathrm{PH}$ domain for phosphoinositides or other ligands in the plasma membrane as follows (Fig. 7); (i) in IRS-1, as the interaction between its $\mathrm{PH}$ domain and the phosphoinositides is weak, the intact interaction of the IRS-3 PTB domain with the NPXpY motif of the insulin receptor is essential for the tyrosine phosphorylation of the chimeric protein; (ii) the insulin-independent localization of wild-type IRS-3 to the plasma membrane via its $\mathrm{PH}$ domain easily couples with the activated insulin receptor even in the presence of the interaction between the PTB domain of IRS-3 and the Y960F insulin receptor which is too weak to be detected by two-hybrid assay [38]; (iii) high-affinity binding of the PH domain of Gab1 to phospholipids in the plasma membrane enables tyrosine phosphorylation of Gab1 even in the absence of the association with the activated receptor. These models provide a mechanism for the interaction between the insulin receptor and IRSs in which both the PH and PTB domains of IRS proteins cooperatively take part in transmitting the insulin signal from the receptor.

A recent study showed that both $\mathrm{PI}(3,4,5) \mathrm{P}_{3}$ and $\mathrm{PI}(4,5) \mathrm{P}_{2}$ are in vitro ligands for the $\mathrm{PH}$ domain of IRS-1 [46]. If so, IRS-1 should be localized to the 


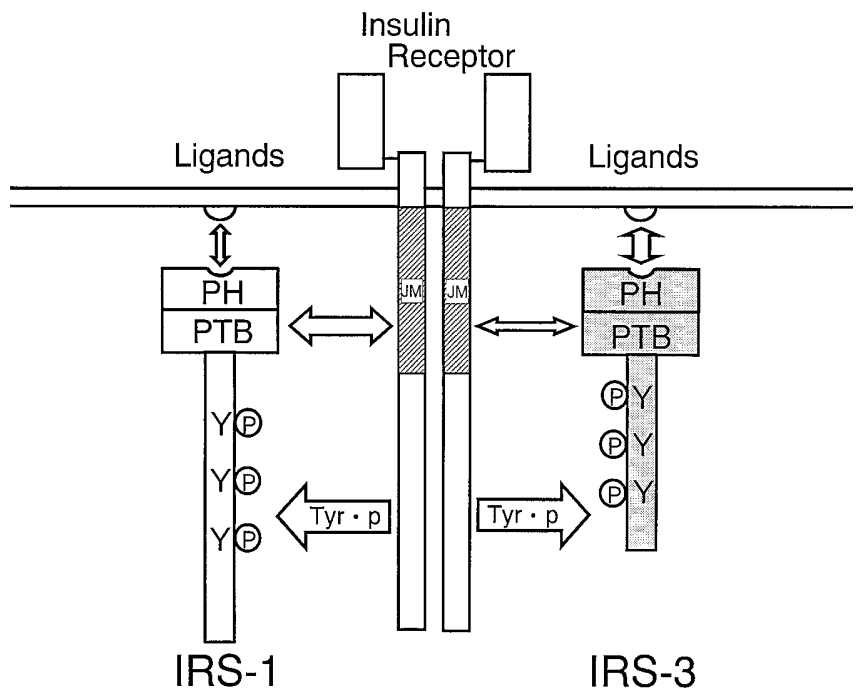

Fig. 7. A model for insulin-induced tyrosine phosphorylation of IRS.

The PH domain and the PTB domain of IRS interact with the ligands and the insulin receptor in the plasma membrane, respectively. As the affinity of the $\mathrm{PH}$ domain for ligands in the plasma membrane is low, intact interaction of the PTB domain of IRS-3 with the juxtamembrane (JM) region of the insulin receptor is essential for insulin-induced tyrosine phosphorylation (Tyr $\bullet$ P) of IRS-1. In contrast, as wild-type IRS-3 is localized to the PM even in the absence of insulin which seems to be due to the higher affinity of its $\mathrm{PH}$ domain for ligands in the plasma membrane, minimal interaction between the receptor JM region with the Y960F mutation and the PTB domain of IRS-3 is sufficient for insulin-induced tyrosine phosphorylation of IRS-3. Thus, the interactions through the two domains cooperatively determine insulin-induced tyrosine phosphorylation of the IRS protein

plasma membrane irrespective of the insulin treatment because the abundance of $\mathrm{PI}(4,5) \mathrm{P}_{2}$ is much greater than $\mathrm{PI}(3,4,5) \mathrm{P}_{3}$ even in stimulated cells [49]. We showed the insulin-stimulated accumulation of IRS-1 to the plasma membrane in a wortmannin-sensitive manner, indicating that the $\mathrm{PH}$ domain of IRS1 has a higher affinity for PI 3-kinase-regulated phosphoinositides rather than $\mathrm{PI}(4,5) \mathrm{P}_{2}$ or membrane proteins with acidic peptide motifs such as nucleolin [50] in insulin-stimulated cells. As plasma membranes from insulin-stimulated and wortmanninstimulated cells still preserved low IRS-1 labelling comparable to that from unstimulated cells, the results also suggest that in a basal state, $\mathrm{PI}(4,5) \mathrm{P}_{2}$ or other molecules are involved in the localization of IRS-1. The analyses of the PH domains of IRSs tagged with green fluorescent protein (GFP) showed that the IRS-1 and IRS-2 PH domains tagged with GFP were translocated to the plasma membrane in response to insulin in a way sensitive to PI 3-kinase inhibitors such as wortmannin and LY294002. In contrast, the IRS-3 PH domain tagged with GFP was constitutively localized to the plasma membrane even in the presence of the PI 3-kinase inhibitors
[51]. That study, using in vitro binding assay, showed that the $\mathrm{PH}$ domain of IRS-1 preferentially binds to $\mathrm{PI}(3,4,5) \mathrm{P}_{3}$ whereas the PTB domain of IRS-3 binds to $\mathrm{PI}(3) \mathrm{P}$. However, the distribution of IRS-3 with the affinity of its $\mathrm{PH}$ domain to the phosphoinositides might not be consistent because the FYVE domain, which preferentially binds to PI(3)P, was shown to be highly enriched in endosomes but not in the plasma membrane [52]. Thus, it is certain $\mathrm{PI}(3,4,5) \mathrm{P}_{3}$ is the native ligand of the $\mathrm{PH}$ domain of IRS-1 in insulin-stimulated cells, although the physiological targets of the PH domain of other IRSs as well as that of the PH domain of IRS- 1 in the basal state have not been identified.

Taken together, the analyses of chimeric IRS-1 and IRS-3 proteins showed that firstly, the $\mathrm{PH}$ domains of IRS-1 and IRS-3 interact in distinct fashions with the phospholipids in the plasma membrane causing the different subcellular distribution of these IRSs, and secondly, the extent of the receptor-substrate interaction required for efficient IRS tyrosine phosphorylation seems to be influenced by the affinity of the $\mathrm{PH}$ domain for the phospholipids in the plasma membrane, indicating that the PH domain and the PTB domain of IRSs cooperatively function in insulinstimulated tyrosine phosphorylation of these proteins.

Acknowledgements. This work was supported in part by Grant No. 192125 from the Juvenile Diabetes Foundation International (to T. Kadowaki) and a grant for diabetes research from the Ohtsuka Pharmaceutical Co., Ltd. (to T. Kadowaki) and Grant No. 11671132 from the Japanese Ministry of Education, Science, Culture and Sports (to S. Satoh) and Grants in Support of the promotion of Research at Yokohama City University (to S. Satoh).

\section{References}

1. Sun XJ, Rothenberg P, Kahn CR et al. (1991) Structure of the insulin receptor substrate IRS-1 defines a unique signal transduction protein. Nature 352: 73-77

2. Sun XJ, Wang LM, Zhang Y et al. (1995) Role of IRS-2 in insulin and cytokine signalling. Nature 377: 173-177

3. Lavan BE, Lane WS, Lienhard GE (1997) The $60-\mathrm{kDa}$ phosphotyrosine protein in insulin-treated adipocytes is a new member of the insulin receptor substrate family. J Biol Chem 272: 11439-11443

4. Lavan BE, Fantin VR, Chang ET, Lane WS, Keller SR, Lienhard GE (1997) A novel 160-kDa phosphotyrosine protein in insulin-treated embryonic kidney cells is a new member of the insulin receptor substrate family. J Biol Chem 272: 21403-21407

5. Holgado-Madruga M, Emlet DR, Moscatello DK, Godwin AK, Wong AJ (1996) A Grb2-associated docking protein in EGF- and insulin-receptor signalling. Nature 379: 560-564

6. Pronk GJ, McGlade L, Pelicci G, Pawson T, Bos JL (1993) Insulin-induced phosphorylation of the $46-$ and $52-\mathrm{kDa}$ Shc proteins. J Biol Chem 268: 5748-5753

7. Sun XJ, Pons S, Wang LM et al. (1997) The IRS-2 gene on murine chromosome 8 encodes a unique signalling adapter 
for insulin and cytokine action. Mol Endocrinol 11: 251-262

8. White MF (1997) The insulin signalling system and the IRS proteins. Diabetologia 40: S2-S17

9. Yamauchi T, Kaburagi Y, Ueki K et al. (1998) Growth hormone and prolactin stimulate tyrosine phosphorylation of insulin receptor substrate- $1,-2$, and -3 , their association with p85 phosphatidylinositol 3-kinase (PI3-kinase), and concomitantly PI3-kinase activation via JAK2 kinase. J Biol Chem 273: 15719-15726

10. Bohni R, Riesgo-Escovar J, Oldham S et al. (1999) Autonomous control of cell and organ size by CHICO, a Drosophila Homolog of vertebrate IRS1-4. Cell 97: 865-875

11. Tamemoto H, Kadowaki T, Tobe K et al. (1994) Insulin resistance and growth retardation in mice lacking insulin receptor substrate-1. Nature 372: 182-186

12. Araki E, Lipes MA, Patti ME et al. (1994) Alternative pathway of insulin signalling in mice with targeted disruption of the IRS-1 gene. Nature 372: 186-190

13. Withers DJ, Gutierrez JS, Towery H et al. (1998) Disruption of IRS-2 causes type 2 diabetes in mice. Nature 391: 900-904

14. Liu SC, Wang Q, Lienhard GE, Keller SR (1999) Insulin receptor substrate 3 is not essential for growth or glucose homeostasis. J Biol Chem 274: 18093-18099

15. Fantin VR, Wang Q, Lienhard GE, Keller SR (2000) Mice lacking insulin receptor substrate 4 exhibit mild defects in growth, reproduction, and glucose hemostasis. Am J Physiol 278: E127-E133

16. Sciacchitano S, Taylor SI (1997) Cloning, tissue expression, and chromosomal localization of the mouse IRS-3 gene. Endocrinology 138: 49331-49340

17. Fantin VR, Lavan BE, Wang Q et al. (1999) Cloning, tissue expression, and chromosomal location of the mouse insulin receptor substrate 4 gene. Endocrinology 140: 1329-1337

18. Ross SA, Lienhard GE, Lavan BE (1998) Association of insulin receptor substrate 3 with $\mathrm{SH} 2$ domain-containing proteins in rat adipocytes. Biochem Biophys Res Commun 247: 487-492

19. Fantin VR, Sparling JD, Slot JW, Keller SR, Lienhard GE, Lavan BE (1998) Characterization of insulin receptor substrate 4 in human embryonic kidney 293 cells. J Biol Chem 273: 10726-10732

20. Clark SF, Martin S, Carozzi AJ, Hill MM, James DE (1998) Intracellular localization of phosphatidylinositide 3-kinase and insulin receptor substrate- 1 in adipocytes: potential involvement of a membrane skeleton. J Cell Biol 140: 1211-1225

21. Clark SF, Molero J-C, James DE (2000) Release of insulin receptor substrate proteins from an intracellular complex coincides with the development of insulin resistance. J Biol Chem 275: 3819-3826

22. Anai M, Ono H, Funaki M et al. (1998) Different subcellular distribution and regulation of expression of insulin receptor substrate (IRS)-3 from those of IRS-1 and IRS-2. J Biol Chem 273: 29686-29692

23. Yamauchi T, Tobe K, Tamemoto H et al. (1996) Insulin signalling and insulin actions in the muscles and livers of insulin-resistant, insulin receptor substrate 1-deficient mice. Mol Cell Biol 16: 3074-3084

24. Kaburagi Y, Satoh S, Tamemoto H et al. (1997) Role of insulin receptor substrate-1 and pp60 in the regulation of insulin-induced glucose transport and GLUT4 translocation in primary adipocytes. J Biol Chem 272: 25839-25844

25. Higuchi R, Krummel B, Sakai RK (1989) A general method of in vitro preparation and specific mutagenesis of
DNA fragments: study of protein and DNA interactions. Nucleic Acids Res 16: 7351-7367

26. Kadowaki H, Kadowaki T, Wondisford FE, Taylor SI (1989) Use of polymerase chain reaction catalyzed by Taq DNA polymerase for site-specific mutagenesis. Gene 76: 161-166

27. Yamamoto-Honda R, Honda Z, Ueki K et al. (1996) Mutant of insulin receptor substrate-1 incapable of activating phosphatidylinositol 3-kinase did not mediate insulin-stimulated maturation of Xenopus laevis oocytes. J Biol Chem 271: 28677-28681

28. Ullrich A, Bell JR, Chen EY et al. (1985) Human insulin receptor and its relationship to the tyrosine kinase family of oncogenes. Nature 313: 756-761

29. Kaburagi Y, Momomura K, Yamamoto-Honda R et al. (1993) Site-directed mutagenesis of the juxtamembrane domain of the human insulin receptor. J Biol Chem 268: 16610-16622

30. Okada T, Kawano Y, Sakakibara T, Hazeki O, Ui M (1994) Essential role of phosphatidylinositol 3-kinase in insulininduced glucose transport and antilipolysis in rat adipocytes. Studies with a selective inhibitor wortmannin. J Biol Chem 269: 3568-3573

31. Robinson LJ, Pang S, Harris DS, Heuser J, James DE (1992) Translocation of the glucose transporter (GLUT4) to the cell surface in permialbilized 3T3-L1 adipocytes: effects of ATP insulin, and GTP gamma S and localization of GLUT4 to clathrin lattices. J Cell Biol 117: 1181-1196

32. Johnson GD, Nogueira Araujo GM (1981) A simple method of reducing the fading of immunofluorescence during microscopy. J Immunol Methods 43: 349-350

33. Kaburagi Y, Yamamoto-Honda R, Tobe K et al. (1995) The role of the NPXY motif in the insulin receptor in tyrosine phosphorylation of insulin receptor substrate-1 and Shc. Endocrinology 136: 3437-3443

34. White MF, Livingston JN, Backer JM et al. (1988) Mutation of the insulin receptor at tyrosine 960 inhibits signal transmission but does not affect its tyrosine kinase activity. Cell 54: 641-649

35. Craparo A, O’Neill TJ, Gustafson TA (1995) Non-SH2 domains within insulin receptor substrate-1 and SHC mediate their phosphotyrosine-dependent interaction with the NPEY motif of the insulin-like growth factor I receptor. J Biol Chem 270: 15639-15643

36. Gustafson TA, He W, Craparo A, Schaub CD, O’Neill TJ (1995) Phosphotyrosine-dependent interaction of SHC and insulin receptor substrate 1 with the NPEY motif of the insulin receptor via a novel non-SH2 domain. Mol Cell Biol 15: 2500-2508

37. He W, O’Neill TJ, Gustafson TA (1995) Distinct modes of interaction of SHC and insulin receptor substrate-1 with the insulin receptor NPEY region via non-SH2 domains. J Biol Chem 270: 23258-23262

38. Smith-Hall J, Pons S, Patti ME et al. (1997) The $60 \mathrm{kDa}$ insulin receptor substrate functions like an IRS protein (pp60IRS3) in adipose cells. Biochemistry 26: 8304-8310

39. Xu P, Jacobs AR, Taylor SI (1999) Interaction of insulin receptor substrate 3 with insulin receptor, insulin receptor-related receptor, insulin-like growth factor-1 receptor, and downstream signalling proteins. J Biol Chem 274: 15262-15270

40. Myers MG Jr, Grammer TC, Brooks J et al. (1995) The pleckstrin homology domain in insulin receptor substrate1 sensitizes insulin signalling. J Biol Chem 270: 11715-11718

41. Voliovitch H, Shindler DG, Hadari YR, Taylor SI, Accili D, Zick Y (1995) Tyrosine phosphorylation of insulin re- 
ceptor substrate- 1 in vivo depends upon the presence of its pleckstrin homology region. J Biol Chem 270: 18083-18087

42. Yenush L, Makati KJ, Smith-Hall J, Ishibashi O, Myers MG Jr, White MF (1996) The pleckstrin homology domain is the principal link between the insulin receptor and IRS-1. J Biol Chem 271: 24300-24306

43. Backer JM, Kahn CR, Cahill DA, Ullrich A, White MF (1990) Receptor-mediated internalization of insulin requires a 12-amino acid sequence in the juxtamembrane region of the insulin $\beta$-subunit. J Biol Chem 265: 16450-16454

44. He W, Craparo A, Zhu Y et al. (1996) Interaction of insulin receptor substrate-2 with the insulin and insulin-like growth factor I receptors. Evidence for two distinct phosphotyrosine-dependent interaction domains within IRS-2. J Biol Chem 271: 11641-11645

45. Sawka-Verhelle D, Tartare-Deckert S, White MF, Van Obberghen E (1996) Insulin receptor substrate-2 binds to the insulin receptor through its phosphotyrosine-binding domain and through a newly identified domain comprising amino acids 591-786. J Biol Chem 271: 5980-5983

46. Dhe-Paganon S, Ottinger EA, Nolte RT, Eck MJ, Shoelson SE (1999) Crystal structure of the pleckstrin homologyphosphotyrosine binding (PH-PTB) targeting region of in- sulin receptor substrate 1. Proc Natl Acad Sci USA 96: 8378-8383

47. Rocchi S, Tartare-Deckert S, Murdaca J, Holgado-Madruga M, Wong AJ, Van Obberghen E (1998) Determination of Gab1 (Grb2-associated binder-1) interaction with insulin receptor-signalling molecules. Mol Endocrinol 12: 914-923

48. Isakoff SJ, Cardozo T, Andreev J et al. (1998) Identification and analysis of PH domain-containing targets of phosphatidylinositol 3-kinase using a novel in vivo assay in yeast. EMBO J 17: 5374-5387

49. Czech MP (2000) PIP2 and PIP3: Complex roles at the cell surface. Cell 100: 603-606

50. Burks DJ, Wang J, Towery H et al. (1998) IRS pleckstrin homology domains bind to acidic motifs in proteins. $\mathrm{J}$ Biol Chem 273: 31061-31067

51. Razzini G, Ingrosso A, Brancaccio A, Sciacchitano S, Esposito DL, Falasca M (2000) Different subcellular localization and phosphoinositide binding of insulin receptor substrate protein pleckstrin homology domains. Mol Endocrinol 14: 823-836

52. Gillooly DJ, Morrow IC, Lindsay M et al. (2000) Localization of phophatidylinositol 3-phosphate in yeast and mammlian cells. EMBO J 19: 4577-4588 